MATEC Web of Conferences 22,04022 (2015)

DOI: $10.1051 /$ matec conf/ 20152204022

(C) Owned by the authors, published by EDP Sciences, 2015

\title{
Study on Influence of Mud Pollution on Formation Fracture Pressure
}

\author{
Hui Xiao \\ Chongqing Key Laboratory of Complex Oil \& Gas Fields Exploration and Development, Chongqing University \\ of Science and Technology, Chongqing, China
}

Hongsheng Tao, Hongjun Qiao \& Jingfu Mu

Research Institute of Shaanxi Yanchang Petroleum (Group) Co., Ltd, Xi'an, Shaanxi, China

Sha Dong

Southwest Oil/gas Field Co. Gas Production Engineering Research Institute, CNPC, Guanghan, Sichuan, China

\begin{abstract}
The mud pollution may change the mechanical properties of rock during oil and gas drilling process, which affects the prediction of fracture pressure, leads to the failure of hydraulic fracturing treatment. Therefore, it is necessary to study influence of mud pollution on formation fracture pressure to improve the forecasting accuracy. The mud pollution has influences on the modulus of elasticity and the Poisson's ratio of rock by the mud pollution experiment, the core microstructure is observed around the mud pollution. Based on the experiment and research, the effects of mud pollution on the fracturing pressure are studied by finite element software system ANSYS, the factors such as pollution depth, perforation length and Poisson's ratio of polluted area are taken into account. The result of the experiment indicated that the modulus of elasticity of rock is reduced and the Poisson's ratio of rock is increased by the mud pollution. Through computing and analyzing, it can be concluded that increases in pollution depth and Poisson's ratio can lead to a vast increase in formation fracturing pressure. A calculation example is presented and the results show that the results of this research can provide valuable guidance to the designers of hydraulic fracturing treatment.
\end{abstract}

Keywords: rock mechanics; pollution zone; fracturing pressure; finite element; hydraulic fracturing

\section{INTRODUCTION}

Hydraulic fracturing is an effective method to stimulate in low permeable reservoirs. As the demand of industry for oil and gas increases, the petroleum exploration is improved and developed. The petroleum exploration is targeting high-temperature, deep and dense reservoir, in which the hydraulic fracturing treatment often fails because the fracture pressure is too high to fracture the formation [1-4]. Meanwhile, the rock mechanics properties can be changed by the mud solid particles plug and mud-filtrate invasion during drilling, thus lead to changes in formation fracture pressure. There is a big gap between the forecast fracture pressure and actual result in the field performance of hydraulic fracturing in deep wells, which causes the formation cannot be fractured. The inaccuracy of forecast result is mainly due to lack consideration of mud pollution in the fracture pressure prediction model. At present, the calculation of fracture pressure is mainly based on well-logging information [5-9]. The correlation analysis on theories and the experimental study are necessary to predict the fracture pressure of polluted wells accurately, thus successful ratio of fracture operation can be increased.

\section{EXPERIMENTS OF MUD POLLUTION'S EF- FECT ON ROCK MECHANICS PROPERTIES}

The method to analyze fracture pressure of polluted perforated wells with the finite element method is the same as the elastic finite element method for mechanics. The rock mechanics properties (such as compressive strength, Young's modulus, Poisson's ratio) may be changed at different degrees with the mud pollution during the drilling and completion processes[10], so it is necessary to consider the variation of rock mechanics properties during the period of calculating fracture pressure with the finite element method.

2.1 Mud pollution effects on the rock mechanics parameters

The level of formation pollution and the influence rule for rock mechanics parameters var-iance were obtained by formation pollution experiment. Three cores drawn from Sichuan Basin of a well at the same depth were determined by the instrument of triaxial stress rock mechanics test for their rock mechanics parameters, then mud (the mud used in the experiment is polysulfide drilling mud with density of $1.1 \mathrm{~g} / \mathrm{cm} 3$, viscosity of $39 \mathrm{mPa} . \mathrm{s}, \mathrm{pH} 10$.) pollution experiment was carried out un-der reservoir pressure and temper- 


\section{MATEC Web of Conferences}

ature conditions on this three cores. To simulate different mud soaking time, the first core stays in the mud filtrate for half an hour, the second core stays for an hour and the third core stays for two hours. And after that, this three cores were determined again by the instrument of triaxial stress rock mechanics test for their rock mechanics parameters(The testing confining pressure is $140 \mathrm{MPa}$; the testing temperature is $150^{\circ} \mathrm{C}$; the testing pore pressure is $140 \mathrm{MPa}$ and the maximum axial load is $1000 \mathrm{KN}$ ), the results were shown in Figure 1 and Figure 2.

Figure 1 compares the cores' Young's modulus before and after mud pollution. The first core increases its Young's modulus by 3.3 percent after staying in the mud for half an hour, nevertheless, the second core rapidly lowered its Young's modulus by 11.7 percent after staying in the mud for an hour, and the third core lowered its Young's modulus by 7.4 percent after staying in the mud for two hour. Overall, the cores' Young's modulus is decreased after polluted by drilling mud.

On the contrary, the cores' Poisson's ratio is increased after polluted by drilling mud, shown in Figure 2. The first core's Poisson's ratio is slightly decreased after staying in the mud for half an hour, the second core is rapidly increased its Poisson's ratio by 20.4 percent after staying in the mud for an hour, and the third core is increased its Poisson's ratio by 15.4 percent after staying in the mud for two hour.

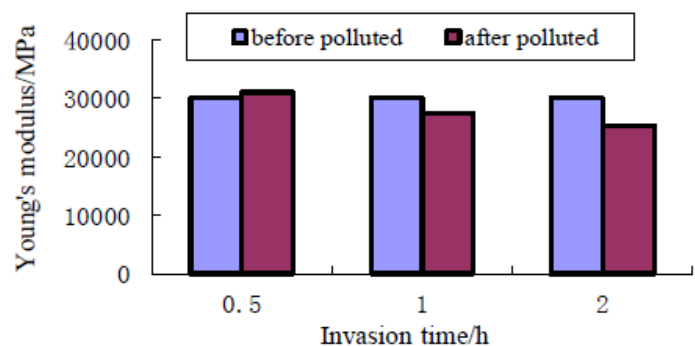

Figure 1. Young's modulus contrast before and after being polluted

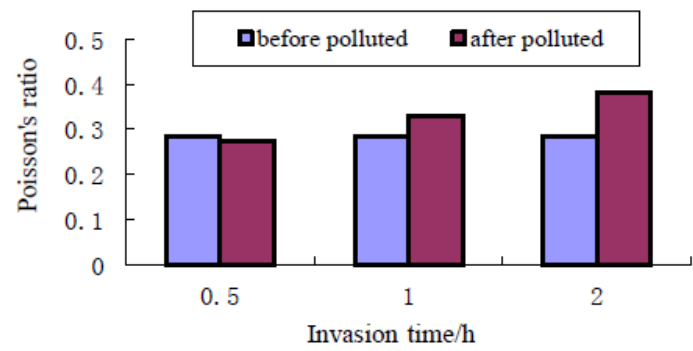

Figure 2. Poisson's ratio contrast before and after being polluted

The reason why the core's Young's modulus is in- creased in short pollution time is that the mud filtrate and part of solid particles of mud invade the core under the pressure drawdown, and then the solid particles destroyed the core's connectivity by filling in the core's big channel to make the strength increased. With the extension of pollution time, more and more mud filtrate invade core's channel and hit on the rock to loosen core's structure, so the Young's modulus is decreased and Poisson's ratio is increased.

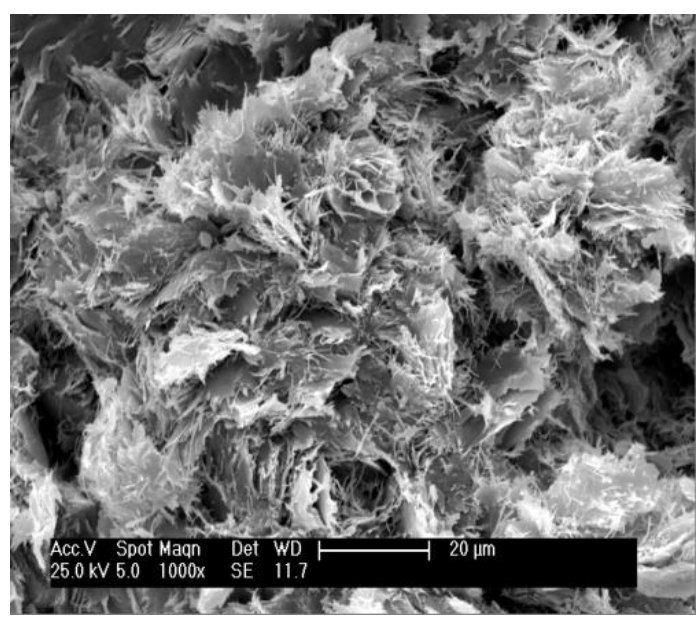

(a)

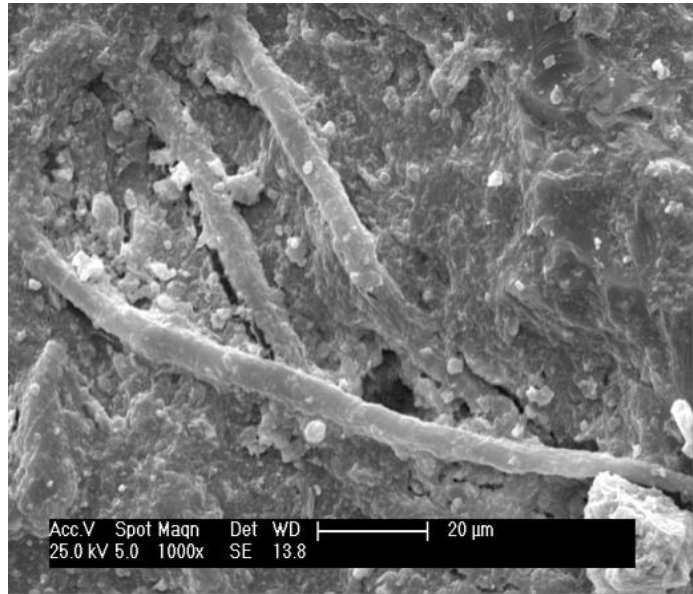

(b)

Figure 3. Microscopic structure of the core before (a) and after (b) polluted

\subsection{Microstructure before and after polluted by mud}

Obvious pore profile and typical filamentous structure of illite are observed in the microgram (Figure 3(left)) of the core before polluted by mud. It is not hard to find that the original intergranular pore is mostly packed by kaolinite and illite, and the surface of ma- 
trix is packed by clay minerals. The figure on the right in Figure 3 is the microscopic structure magnified 1000 times of the same core after polluted by mud. It is found that the pore profile is no longer obvious, simultaneously, the filamentous polymer and barite can be seen clearly.

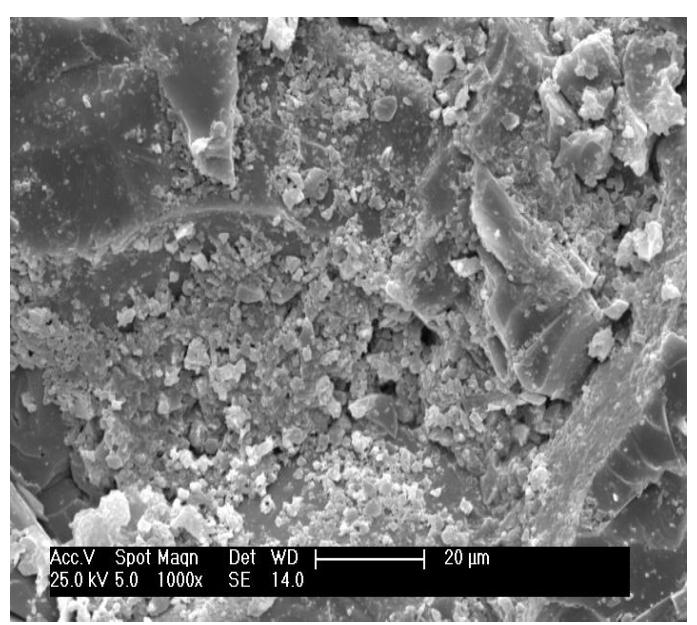

(a)

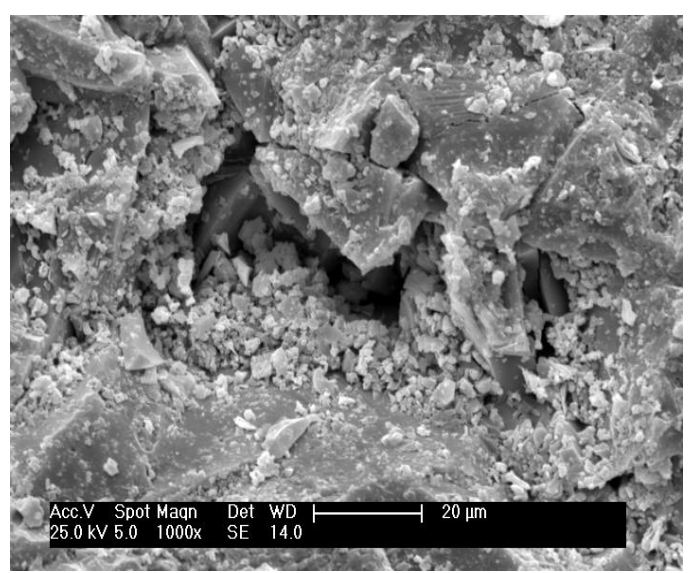

(b)

Figure 4. Microscopic structure of the core distance from the pollution face $5 \mathrm{~mm}$ (a) and $15 \mathrm{~mm}$ (b) away

Figure 4 is the microscopic structure of the polluted core, which is away from the pollution face for about $5 \mathrm{~mm}$ and $15 \mathrm{~mm}$. Figure 5 is the microscopic structure of the core, which is away from the pollution face for about $25 \mathrm{~mm}$ and $40 \mathrm{~mm}$. It's found that the big channel is firstly filled by the invader, the amount of filamentous polymer and barite invaded in the channel tend to be decreased as the distance from the pollution face is increased. When the distance from the pollution face reaches $40 \mathrm{~mm}$, the pore profile can be clearly observed. That is to say, the mud stops to invade the core for $40 \mathrm{~mm}$ away from the surface of the core (the core is $50 \mathrm{~mm}$ long).

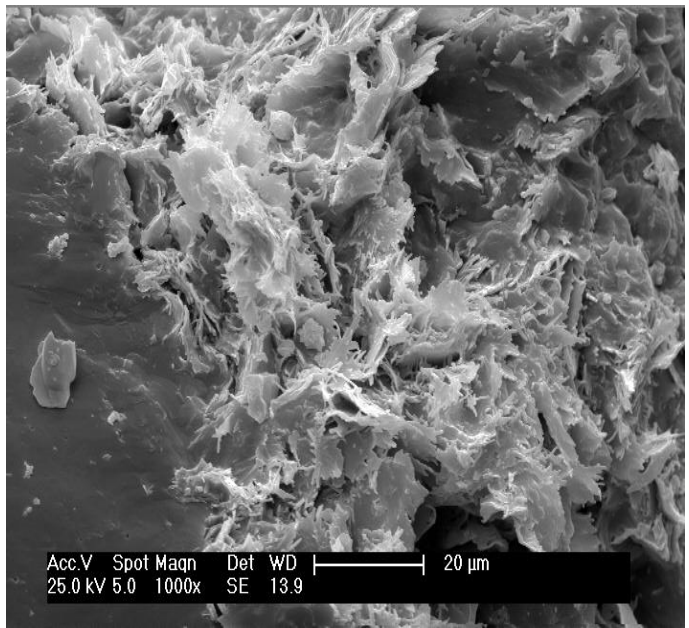

(a)

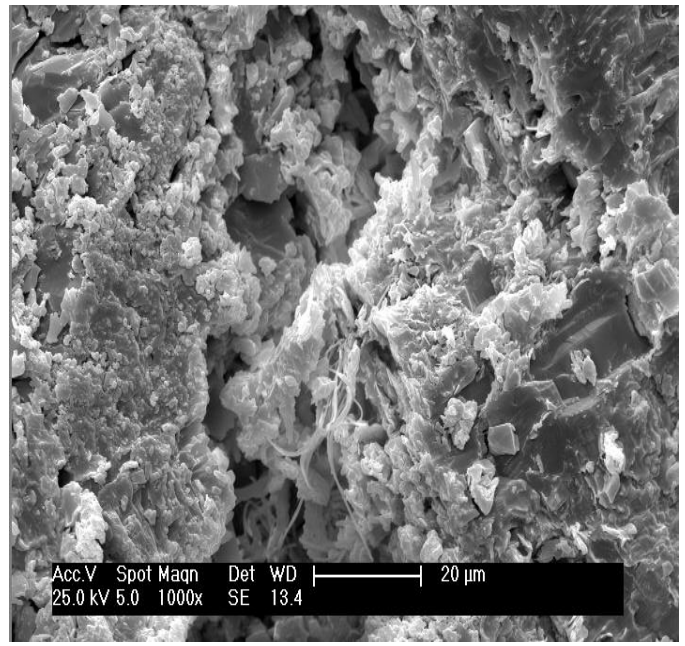

(b)

Figure 5. Microscopic structure of the core distance from the pollution face $25 \mathrm{~mm}$ (a) and $40 \mathrm{~mm}$ (b) away

\subsection{Conclusion of the experiment}

The experiment in lab shows that the mud pollution will change the rock mechanics parameters of the formation, that is, the Young's modulus is decreased and the Poisson's ratio is increased. All of these cause the stress field around the wellbore to change. There is an invasion depth of mud can be observed by the microscopic structure of the core after polluted by the mud, that is to say, there are two regions of different mechanics properties in the polluted core: One is the pollution area, and another one is unpolluted area. So the pollution area and its size must be taken into account to calculate the fracture pressure of the mud 


\section{MATEC Web of Conferences}

polluted well by finite element method.

\section{FRACTURE PRESSURE PREDICTION FOR MUD POLLUTED PERFORATED WELL}

\subsection{Calculation of polluted rock fracture toughness}

Currently, the routine calculation methods for rock fracture toughness have their shortcoming and difficulty to a certain extent. The rock fracture toughness can be calculated by the statistical relationship among the rock fracture toughness, hardness index, uniaxial compressive strength and Young's modulus [11-13].

The relationship among the rock's uniaxial compressive strength, shale content and dynamic Young's modulus is shown as follows [14]:

$\sigma_{\mathrm{c}}=(0.0045+0.003 V) E$

The rock tensile strength can be calculated by:

$\sigma_{\mathrm{c}}=\sigma_{\mathrm{c}} / K(K=8 \sim 15)$

That is:

$\sigma_{\mathrm{c}}=\sigma_{\mathrm{c}}[0.0045 \mathrm{E}(1-\mathrm{V})+0.008 \mathrm{~V}] / \mathrm{K}$

The confining pressure $\mathrm{P}_{\mathrm{C}}$ can be calculated by:

$P_{\mathrm{c}}=\frac{\mu}{1-\mu}\left(P_{v}-\alpha P_{\mathrm{P}}\right)+\alpha P_{\mathrm{P}}$

According to the statistical, the relationship between rock fracture toughness $\mathrm{K}_{\mathrm{IC}}$ and confining pressure $P_{\mathrm{c}}$ is shown as follows:

$K_{\mathrm{IC}}=0.217 P_{\mathrm{c}}+0.2953(R=0.99)$

The relationship among rock fracture toughness, deep confining pressure and tensile strength is shown as follows:

$K_{\mathrm{IC}}=0.217 P_{\mathrm{c}}+0.0059 \sigma_{\mathrm{t}}^{3}+0.0923 \sigma_{\mathrm{t}}^{2}$

$$
+0.571 \sigma_{\mathrm{t}}-0.3322(R=0.95)
$$

Where $E=$ Young's modulus; $\mu=$ Poisson's ratio; $V=$ shale content ${ }^{P_{v}}=$ overlying formation pressure; ${ }^{P_{p}}$ $=$ pore pressure; $\sigma_{\mathrm{C}}=$ uniaxial compressive strength; $\mathrm{P}_{\mathrm{C}}$ $=$ confining pressure; $\sigma_{\mathrm{t}}=$ uniaxial tensile strength; $\alpha$ $=$ elastic parameters.

\subsection{Pollution depth's influence on fracture pressure}

So far, there is no certain method to ascertain the pollution zone precisely. The depth of pollution zone is generally considered to be $600 \mathrm{~mm} \sim 1200 \mathrm{~mm}$ after drilling and completion [15].

The ANSYS-international large-scale general-purpose finite element software is adopted to calculate fracture pressure under influence of mud pollution. The size of formation model is $3000 \mathrm{~mm} * 3000 \mathrm{~mm}$, for improving the calculating efficiency, the size of simulation model is half of the formation model. The maximum horizontal principal stress is $85.5 \mathrm{MPa}$; the minimum horizontal principal stress is $85.5 \mathrm{MPa}$; the vertical stress is $110.5 \mathrm{MPa}$, and the pore pressure is $53.2 \mathrm{MPa}$. The radius of well bore is $50 \mathrm{~mm}$; perforation diameter is $10 \mathrm{~mm}$; perforation length is $500 \mathrm{~mm}$; perforation azimuth is zero. Young's modulus and Poisson's ratio of pollution zone are respectively $18000 \mathrm{MPa}$ and 0.27 , while Young's modulus and Poisson's ratio of unpolluted zone are respectively $25000 \mathrm{MPa}$ and 0.25 . The compressive strength and critical stress-intensity factor of pollution zone are respectively $247.6 \mathrm{MPa}$ and $32.7 \mathrm{MPa}^{\prime} \mathrm{m} 1 / 2$. There are five simulation models with five different pollution depths $(600 \mathrm{~mm}, 700 \mathrm{~mm}$, $800 \mathrm{~mm}, 900 \mathrm{~mm}$, and $1000 \mathrm{~mm}$ ). The tensile strength failure criterion is used to determine whether the formation is a failure or not. Figure 6 is the schematic of pollution zone in simulation model. Figure 7 is the stress contour when the model cracks.

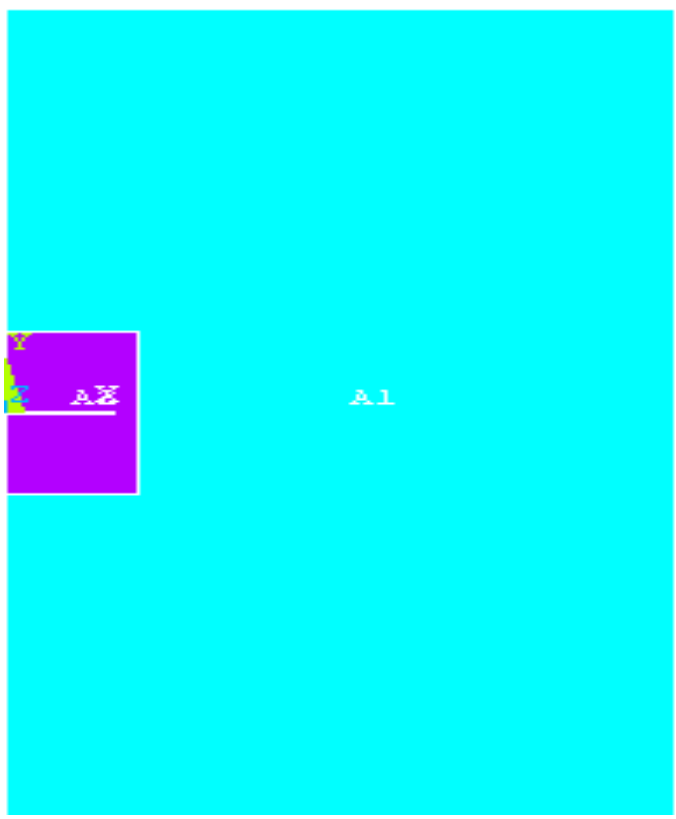

Figure 6. Scheme of pollution region (depth of pollution region is $600 \mathrm{~mm}$, dark area)

Figure 8 is the curve between the fracture pressure and the pollution depth, the fracture pressure is in creased with increasing pollution depth. As the pollution depth is increased from $0.6 \mathrm{~m}$ to $1 \mathrm{~m}$, the fracture pressure is increased by $2.78 \mathrm{MPa}$.

Figure 9 is the curve between the fracture pressure and the pollution depth after the pollution region was traversed, the perforation length is $500 \mathrm{~mm}$. As shown in Figure 9, the pollution depth is increased from $0 \mathrm{~m}$ to $0.4 \mathrm{~m}$, the fracture pressure is increased from 93.1 MPa to $93.49 \mathrm{MPa}$ but the changes of fracture pressure were not obvious. 


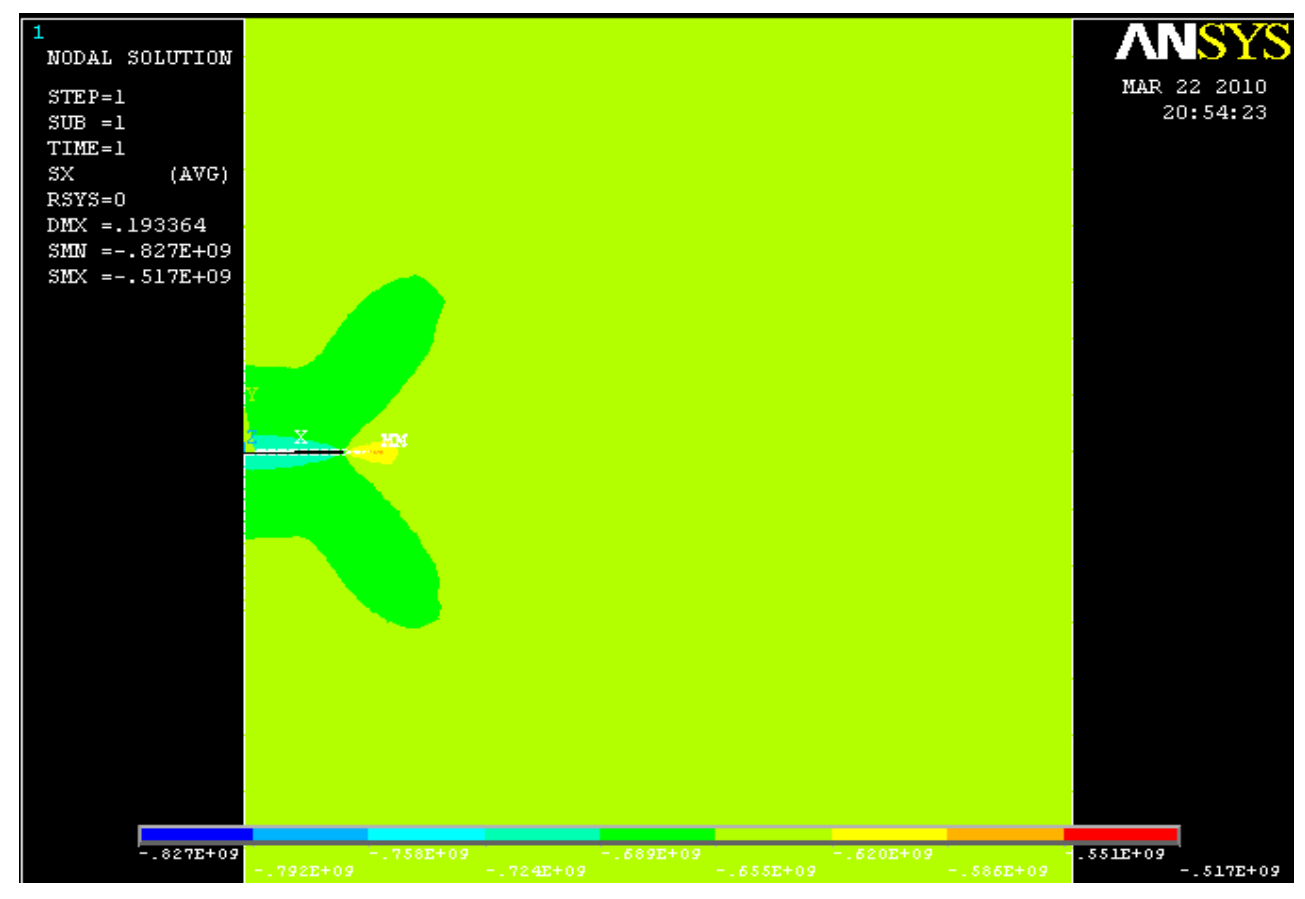

Figure 7. Displacement equivalence value map in the X-direction (pollution depth is $600 \mathrm{~mm}$ )

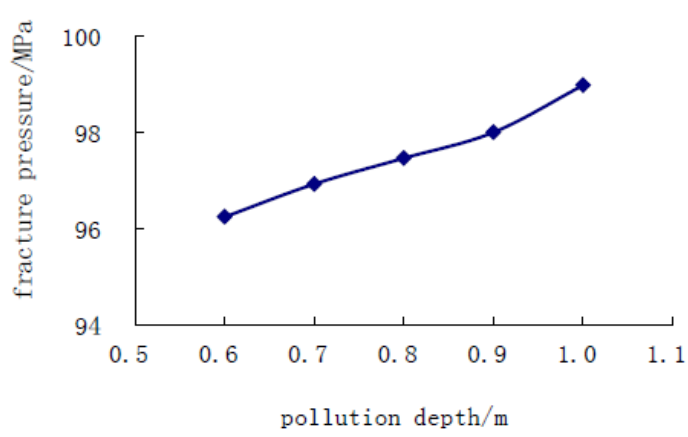

Figure 8. Curves between fracture pressure and pollution depth

\subsection{Influence of Poisson's ratio of pollution area on fracture pressure}

There are five simulation models with five different Poisson's ratios of pollution area $(0.27,0.28,0.29,0.30$, and 0.31 ). The perforation length is $600 \mathrm{~mm}$; the radius of well bore is $50 \mathrm{~mm}$; the perforation diameter is $10 \mathrm{~mm}$; the Young's modulus of pollution area is $25000 \mathrm{MPa}$; the pore pressure is $53.2 \mathrm{MPa}$; the perforation axis is in the direction of maximum horizontal principal stress; the pollution depth is $700 \mathrm{~mm}$. Figure 10 is the curve between the fracture pressure and the Poisson's ratio. As shown in Figure 10, the fracture pressure is increased with the Poisson's ratio. As the Poisson's ratio is increased from 0.31 to 0.26 , the fracture pressure is increased by nearly $5 \mathrm{MPa}$. Thus it can be seen that the mud pollution changes the formation fracture pressure, and we must take action to relieve pollutions to reduce fracture pressure for the deep formation of pollution.

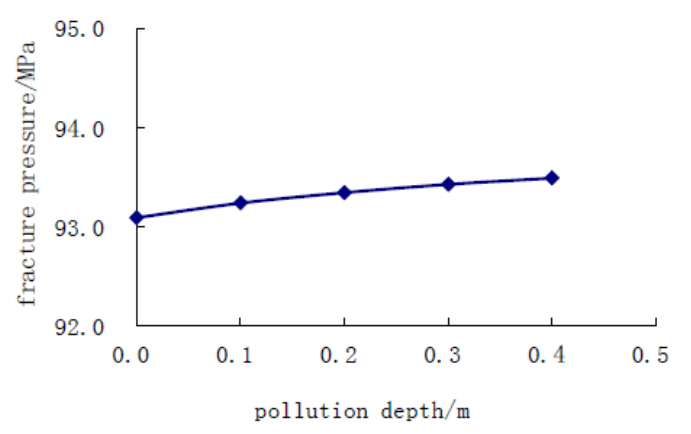

Figure 9. Curves between fracture pressure and pollution depth after the pollution region was traversed

\section{CASE STUDY}

Well PL-3 in Sichuan Basin is a vertical well, its target zone is the 2nd Xu Member, the depth of target zone is $3800 \mathrm{~m}$, and the reservoir belongs to porous type. Acid treatment is operated in well PL-3 before fracturing, and the well-head pressure of acid treatment is up to $83 \mathrm{MPa}$ when the pumping rate is $2.5 \mathrm{~m}^{3} / \mathrm{min}$. 
MATEC Web of Conferences

Table 1. Input parameters

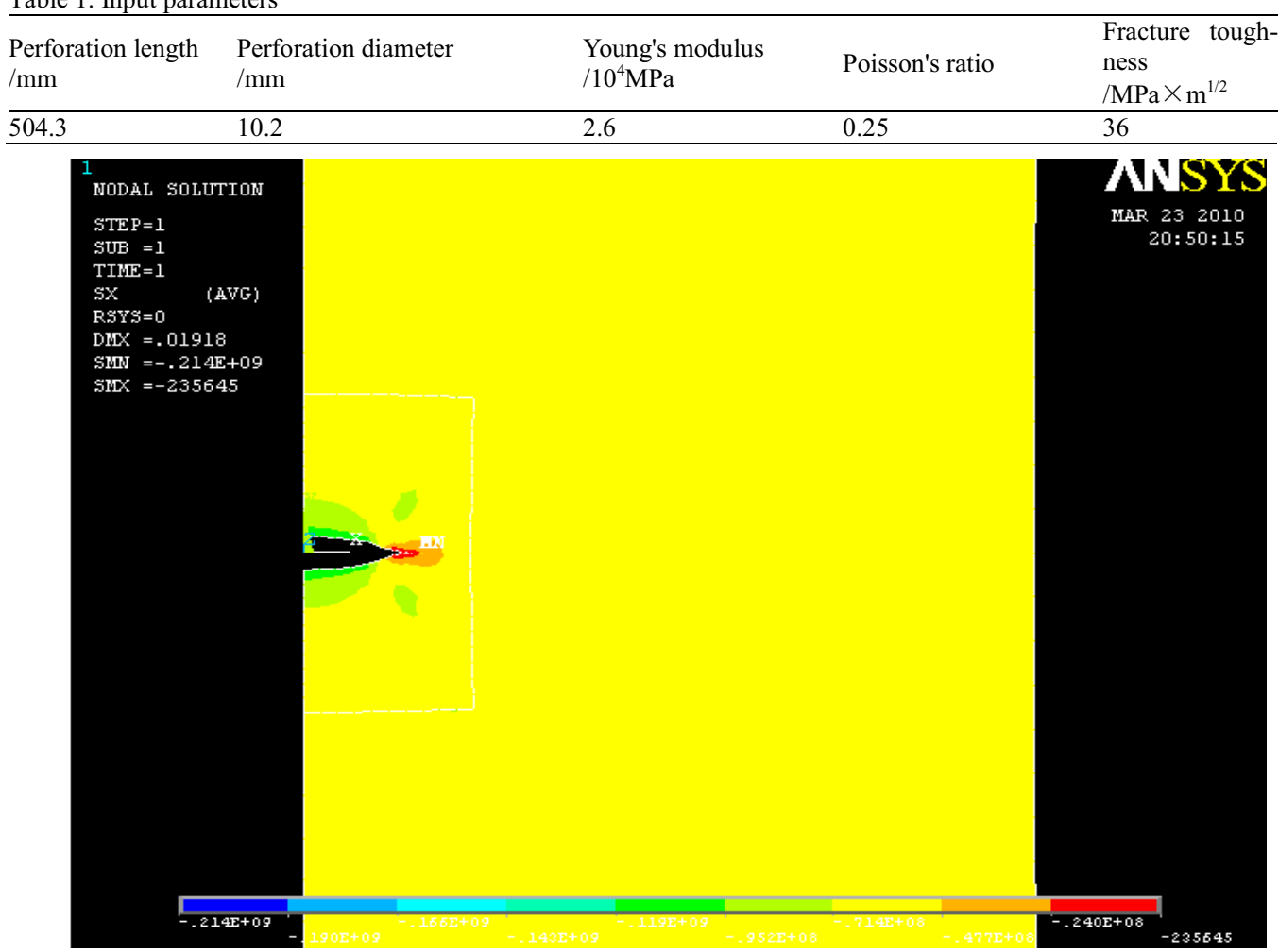

Figure 11. Displacement equivalence value map in the X-direction (after being polluted)

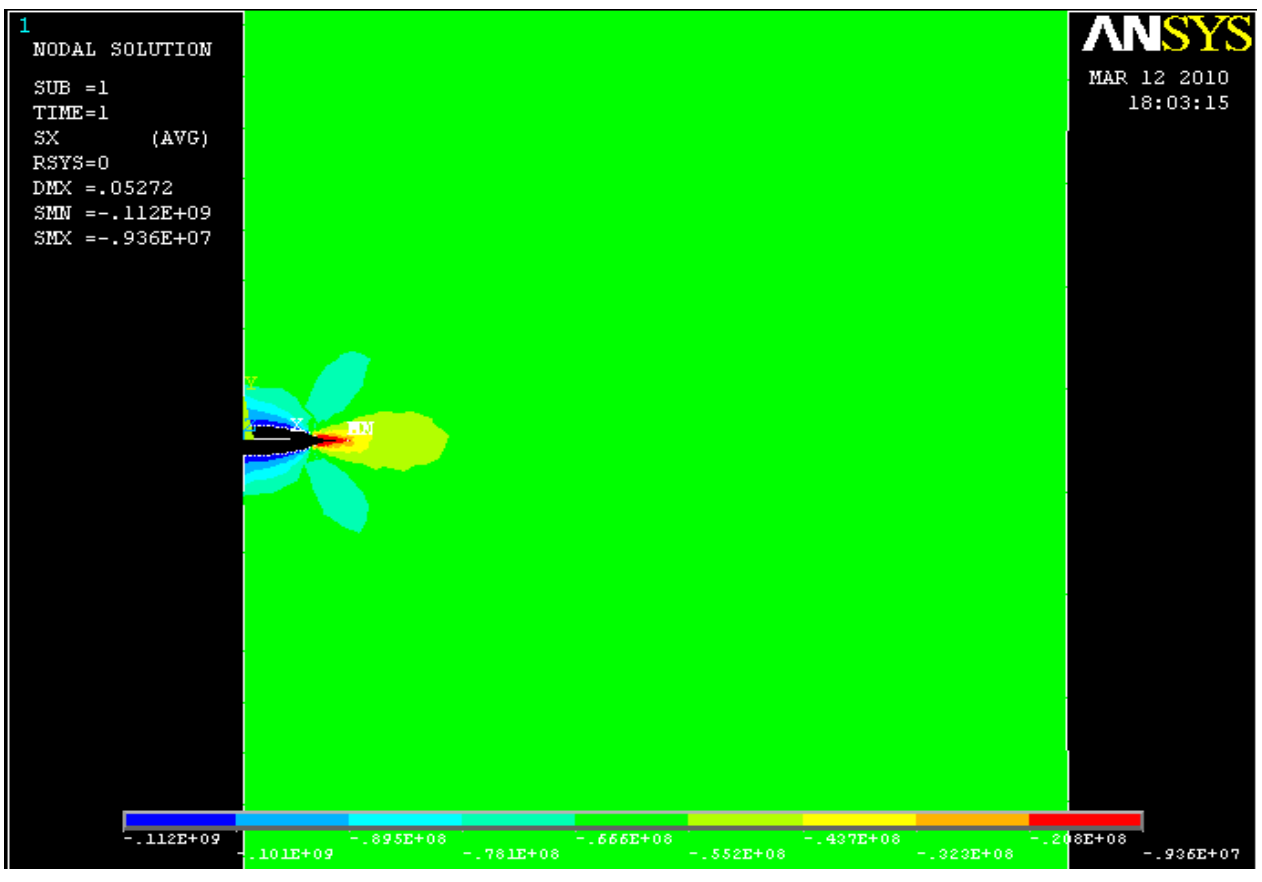

Figure 12. Displacement equivalence value map in the X-direction (after the pollution being relieved) 
ICETA 2015

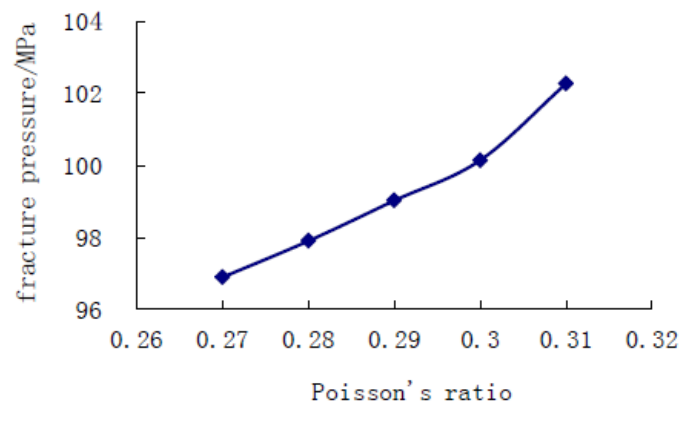

Figure 10. Curves between fracture pressure and Poisson's ratio

Based on the well's basic date and the results of mud pollution experiment, the formation fracture pressure after polluted is predicted by the finite element model. The input parameters are listed in Table 1; Figure 11 delineates the displacement equivalence value map in the X-direction after the formation polluted by mud. The fracture pressure is forecast to $112.1 \mathrm{MPa}$, and that's what led to high treatment well-head pressure in acid treatment.

After the mud pollution being relieved by acidizing, the predicting formation fracture pressure is $99.4 \mathrm{MPa}$. Figure 12 delineates the displacement equivalence value map in the $\mathrm{X}$-direction. The hydraulic fracturing treatment was implemented smoothly on Well PL-3. The predicting formation fracture pressure was consistent with the field treatment monitor fracture pressure.

\section{CONCLUSIONS}

(1)In the mud pollution experiment, the Young's modulus is increased at initial pollution stage and then declined; on the contrary, the Poisson's ratio is declined at initial pollution stage and then increases. Finally, the Young's modulus is declined and the Poisson's ratio is increased.

(2)The fracture pressure is increased with increasing pollution depth before the pollution region being traversed, but the changes of fracture pressure are not obvious after the pollution region being traversed.

(3)The fracture pressure is increased with the Poisson's ratio of pollution area. As the Poisson's ratio is increased from 0.31 to 0.26 , the fracture pressure is increased by nearly $5 \mathrm{MPa}$.

\section{REFERENCES}

[1] Huang Hui, Tan Mingwen. \& Zhang Shaobin, et al 2004. Difficulty of gas reservoir fracturing and its technology countermeasures in Xujiahe formation in western
Sichuan. Drilling \& Production Technology, 27(5): 27-30.

[2] M. J. Mayerhofer. Results of U.S. Department of Energy Deep Gas Well Stimulation Study.spe95639.

[3] Weijers, L. G. Griffin. The First Successful Fracture Treatment Campaign Conducted in Japan: Stimulation Challenges in a Deep, Naturally Fractured Volcanic Rock.spe 77678 .

[4] L. Weijers, L.G. Griffin. Hydraulic Fracturing in a Deep, Naturally Fractured Volcanic Rock in Japan Design Considerations and Execution Results.spe77823.

[5] Yang lei, Wang Hongliang. \& Mao Shangming, et al. 2002. Applied research on fracture pressure prediction. Journal of Xinjiang Petroleum Institute, 14(4): 67-68.

[6] Guo Kaijun. \& Chang Peifeng. 2004. Study on prediction of fracturing pressure of shallow layer. Chinese Journal of Rock Mechanics and Engineering, 23(14): 2484-2487.

[7] Holbrook P W. 1997. Discussion of a new simple method to estimate fracture pressure gradients. SPE Drilling \& Completion, March.

[8] Gu Jun, Gao Deli. \& Yang Changlong, et al. 2004. Predicting formation breakdown pressure by CYT method. Natural Gas Industry, 24(12): 62-64.

[9] Li Sigui, Deng Jingen, Wei Baohua, et al. 2005. Formation fracture pressure calculation in high temperatures wells. Chinese Journal of Rock Mechanics and Engineering. 24(S2): 5669-5672.

[10] Gao Yanxia, Shan Yuming. \& Liu Weiguo, et al. 2007. Characteristics and influencing factors of rock mechanics properties in deep formations of west Sichuan Depression. Petroleum Geology and Recovery Efficiency. 11(14): 23-25.

[11]Chen Zhixi, Chen Mian. \& JIN Yan,et al. 1997. Determination of rock fracture toughness with hydraulic fracturing method. Chinese Journal of Rock Mechanics and Engineering, 16(1): 59-64.

[12]Chen Zhixi, Chen Mian. \& Jin Yan. 1997. Experimental study on the relationship between rock fracture toughness and acoustic velocity. Oil Drilling and Production Technology, 16(2): 59-64.

[13] JIN Yan, Chen Mian. \& Zhang Xudong. 2001. Determination of fracture toughness for deep well rock with geophysical logging data. Chinese Journal of Rock Mechanics and Engineering, 4(20): 454-456.

[14]Deere D U, Miller R P. 1996:1-5. Engineering Classifications and Indes Properties for Intact Rocks. Technical Report No. AFWL-TR-65 -116.

[15]Zhang Yi, Li Gen-sheng. \& Xiong Wei,et al. 2004. Stimulation mechanism of oil well using high-pressure water jet deep-penetrating perforation technique. Journal of the University of petroleum, China, 2(28): 38-41. 